\title{
Comparison of High-resolution Anorectal Manometry With Water-perfused Anorectal Manometry
}

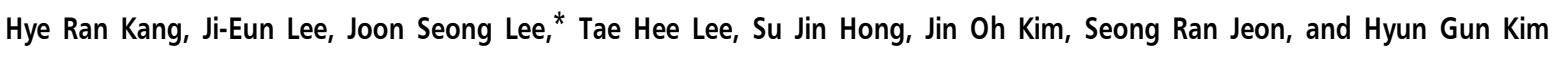 \\ Institute for Digestive Research, Soonchunhyang University, College of Medicien, Seoul, Korea
}

\begin{abstract}
Background/Aims
To date, high-resolution manometry has been used mainly in the study of esophageal motility disorders and has been shown to provide more physiological information than conventional manometry, and is easier to interpret. This study aimed to evaluate the usefulness of high-resolution anorectal manometry (HRARM) compared to water-perfused anorectal manometry.
\end{abstract}

\section{Methods}

Patients who complained of chronic constipation with/without fecal incontinence underwent both water-perfused anorectal manometry and HRARM in a random order on the same day. Resting and squeezing pressures of the anal sphincter, attempted defecation, rectoanal inhibitory reflex, rectoanal contractile reflex, Rao's type of dyssynergia during attempted defecation, anal canal length, defecation dynamic parameters and measurement times for each method were analyzed.

\section{Results}

Of 14 patients, 7 were female, and the median age was 59 years (range 35-77). Indications for manometry were constipation $(n=8)$ and constipation with fecal incontinence $(n=6)$. Resting and squeezing pressures showed that the 2 methods were strongly correlated (resting pressure: $r=0.746, P=0.002$; squeezing pressure: $r=0.921, P<0.001$ ). In attempted defection, one equivocal case with water-perfused anorectal manometry was diagnosed type I pelvic floor dyssynergia with HRARM providing detailed pressure changes in internal and external anal spincters, and puborectalis muscle which improved assessment of anorectal disorders. The measurement time for HRARM was significantly shorter than that for water-perfused anorectal manometry (11.3 vs 23.0 minutes, $P<0.001)$.

\section{Conclusions}

Both water-perfused anorectal manometry and HRARM are well tolerated and reliable methods of evaluating defecation disorders of pelvic floor dysfunction. HRARM is likely to provide better physiological information and to require a shorter measurement time compared to water-perfused anorectal manometry.

\section{(J Neurogastroenterol Motil 2015;21:126-132)}

\section{Key Words}

Constipation; Defecation; Fecal incontinence; Manometry; High-resolution manometry

Received: March 4, 2014 Revised: August 18, 2014 Accepted: August 22, 2014

(C) This is an Open Access article distributed under the terms of the Creative Commons Attribution Non-Commercial License (http://creativecommons. org/licenses/by-nc/3.0) which permits unrestricted non-commercial use, distribution, and reproduction in any medium, provided the original work is properly cited.

*Correspondence: Joon Seong Lee, PhD, MD Institute for Digestive Research, Soonchunhyang University, College of Medicine, Daesagwan-gil 22, Yongsan-gu, Seoul 140-743, Korea

Tel: +82-2-709-9691, Fax: +82-2-709-9696, E-mail: joonlee@schmc.ac.kr

Financial support: This study was supported in part by the Soonchunhyang University Research Fund. Conflicts of interest: None.

Author contributions: Hye Ran Kang contributed to data analysis and interpretation, and drafted the manuscript; Joon Seong Lee designed and coordinated the study, contributed to data interpretation, and edited the manuscript; Ji-Eun Lee, Tae Hee Lee, and Joon Seong Lee collected data and reviewed data analysis; Su Jin Hong, Jin Oh Kim, Seong Ran Jeon, and Hyun Gun Kim edited the manuscript. ORCID: Tae Hee Lee, http://orcid.org/0000-0003-3049-8252; Joon Seong Lee, http://orcid.org/0000-0002-9616-3028. 


\section{Introduction}

Anorectal manometry is a useful diagnostic tool for defecation disorders. The apparatus includes 2 major components. The first is a pressure-sensing transducer that uses two types of probe: a water-perfused catheter and solid-state catheter. The second component of the apparatus is an amplifying and recording system. ${ }^{1,2}$ High-resolution manometry (HRM) allows interpretation of manometric recordings with highly detailed topographical plots of intraluminal pressures relative to time and location. To date, HRM has been used mainly in the study of esophageal motility disorders and has been shown to provide more physiological information and is easier to interpret than conventional manometry. ${ }^{3,4}$ Also, it requires less time than conventional manometry, patients feel comfortable, and lowers the associated cost. ${ }^{5}$ Jones et $\mathrm{al}^{6}$ reported that anorectal HRM is highly correlated with water-perfused manometry measurements. But, there have been fewer studies done on anorectal HRM than on esophageal HRM.

The aim of this study was to evaluate the usefulness of highresolution anorectal manometry (HRARM) using a solid-state catheter compared to water-perfused anorectal manometry to evaluate defecation disorders due to pelvic floor dyssynergia.

\section{Materials and Methods}

\section{Patients}

We performed a prospective study of consecutive patients who visited the outpatient clinic or who were admitted due to chronic constipation with/without fecal incontinence at the Department of Gastroenterology, Soonchunhyang University Hospital, between April 2009 and October 2009. All patients had functional defecation disorders, but some were excluded on the basis of concurrent systemic disorders or metabolic disorders, or in the case of mechanical obstruction diagnosed by patient history, physical examination, serologic testing, barium enema or colonoscopy. Informed consent was obtained from all patients. This study was approved by the Institutional Review Board.

\section{Method}

All 14 patients completed 2 questionnaires regarding the Rome III criteria for functional constipation. Patients underwent both water-perfused anorectal manometry and HRARM on the same day in a random order.

\section{Water-perfused anorectal manometry}

Patients were informed about the test protocol and were asked not to take medication that could affect bowel movement at least 3 days before the test and to defecate on the morning of the test. Patients were studied in the left lateral decubitus position with hips and knees bent to $90^{\circ}$. The study was conducted in a quiet room with no other persons present. A radial catheter with multi-channel circumferential sensors spaced at $0.5-\mathrm{cm}$ intervals (each of $0.8-\mathrm{cm}$ diameter) was gently inserted $6 \mathrm{~cm}$ into the anal verge. After over 5 minutes of making the patient comfortable and allowing the pressures to stabilize, the resting pressure was measured. Patients were asked to squeeze the anus for more than 10 seconds to measure the maximum squeezing pressure. The sphincter pressure was measured by pulling the catheter $1 \mathrm{~cm}$ using the stationary pull-through method for 1 minute, and the assembly was perfused using a low compliance hydraulic capillary infusion system (Arndorfer Medical Specialties, Greendale, USA) with a $0.5 \mathrm{~mL} / \mathrm{min}$ perfusion rate. After 20 seconds of allowing the pressures to stabilize, during attempted defecation for 5 seconds, changes in intra-anal and intra-rectal pressure were measured. The rectoanal inhibitory reflex was assessed by progressively inflating rectal balloon using spiral catheter with circumferential sensors spaced at $0.5-\mathrm{cm}$ intervals with balloon in increments of $10 \mathrm{~mL}$ up to $50-\mathrm{mL}$ air, after which patients were asked to strain their muscles as if to defecate. During coughing, the rectoanal contractile reflex was assessed, changes in intra-anal and intra-rectal pressure were measured. At least 3 measurements were performed to minimize false positives.

\section{High-resolution anorectal manometry}

Preparation for HRARM was the same as for water-perfused anorectal manometry. Patients were studied in the left lateral decubitus position with hips and knees bent to $90^{\circ}$. HRARM was performed using a solid-state manometric assembly with 10 circumferential sensors spaced at 0.7-cm intervals (Sierra Scientific Instruments Inc, Los Angeles, CA, USA). The catheter was gently placed in the rectum, with 1 or 2 sensors located outside the anal canal. After making the patient comfortable and allowing the pressures to stabilize, the resting pressure was measured. Patients were asked to squeeze the anus for more than 20 seconds to measure the maximum squeezing pressure. The intra-rectal and intra-anal pressures were also measured during attempted defecation for 5 seconds. After insertion of the rectal balloon, it 
was inflated in increments of $10 \mathrm{~mL}$ up to $50 \mathrm{~mL}$, and the rectoanal inhibitory reflex was assessed. During coughing, the rectoanal contractile reflex was assessed, changes in intra-anal and intra-rectal pressure were measured. At least 3 measurements were performed to minimize false positives. The pressure detected by the solid-state catheter was reported by a ManoScan system (Sierra Scientific Instruments Inc.), and these manometric data were analyzed using the ManoView analysis software (Sierra Scientific Instruments Inc.).

\section{Analysis}

Analysis is based on recorded data. We compared the anal sphincter resting pressure, maximum squeezing pressure and the ratio of maximum squeezing pressure to resting pressure between water-perfused anorectal manometry and HRARM. Rectoanal inhibitory reflex and rectoanal contractile reflex were assessed and also the correlation between both method. We measured anal canal length and defecation dynamic parameters such as rectoanal pressure gradient, percentage of relaxation and pressure change during cough reflex in both methods. The manometric profiles during attempted defecation were classified into Rao's types of dyssynergia. ${ }^{7}$ During attempted defecation, there is normally an increase in the intrarectal pressure and a decrease in the intra-anal pressure. Type I dyssynergia is characterized by an increased intrarectal pressure with a paradoxical increase in the intra-anal pressure. In type II dyssynergia, the subject is unable to generate an adequate propulsive force together with paradoxic anal contraction. In type III dyssynergia, the subject can generate an adequate propulsive force along with an absent relaxation or incomplete $(\leq 20 \%)$ relaxation of resting anal sphincter pressure. In type IV dyssynergia, the subject is unable to generate an adequate propulsive force together with absent or incomplete relaxation of anal sphincter pressure. The Rao's subtype analyses of water-perfused anorectal manometry and HRARM were conducted by a single researcher blinded to the results of the other method. The rectoanal inhibitory reflex and rectoanal contractile reflex were interpreted by the same method. The measurement time was based on the recording time stored in the computer. Rectoanal pressure gradient is a pressure difference between rectal and anal pressures taken over 2 seconds at the highest rectoanal pressure gradient during pushing period. Percentage of anal relaxation is taken according to: (1-residual anal pressure/anal resting pressure $) \times 100$ where residual anal pressure is taken over 2 seconds.

\section{Statistical Methods}

Correlations between water-perfused anorectal manometry and HRARM for resting pressure and maximum squeezing pressure were analyzed using Pearson's correlation coefficient. All parameters, including measurement time, were compared using a Wilcoxon's signed-rank test or Paired $t$ test. Statistical significance was set at $P<0.05$.

\section{Results}

\section{Patients' Characteristics}

Of the 14 patients, the mean age was 59 years (range 35-77 years). Indications for anorectal manometry were constipation (n $=8)$ and constipation with fecal incontinence $(n=6)$. Patients

Table 1. Baseline Characteristics of Patients With Chronic Constipation $(\mathrm{n}=14)$

\begin{tabular}{lc}
\hline \multicolumn{2}{c}{ Characteristics } \\
\hline Female (n [\%]) & $7(50)$ \\
Age (yr [range]) & $59(35-77)$ \\
Indication for anorectal manometry (n [\%]) & \\
Constipation & $8(57)$ \\
Constipation and fecal incontinence & $6(43)$ \\
Concurrent disease (n [\%]) & $3(21.4)$ \\
Hypertension & $2(14.2)$ \\
Diabetes mellitus & $2(14.2)$ \\
Angina pectoris & $3(21.4)$ \\
Previous history of abdominal surgery & $3(21.4)$ \\
Previous operation for HIVD & $1(7.1)$ \\
Cauda equina syndrome & $1(0-6) /$ day \\
Constipation questionnaire & $4(0-7) /$ week \\
Numbers of defecation (n [range]) & \\
& $100(25-100)$ \\
Percentage of symptom (\%) & $75(0-100)$ \\
Straining & $0(0-100)$ \\
Incomplete evacuation & $0(0-100)$ \\
Obstruction sense & \\
Digitation & $4(0-4)$ \\
Intensity of symptom (0-4) & $4(0-4)$ \\
Straining & $0(0-4)$ \\
Incomplete evacuation & $0(0-4)$ \\
Obstruction sense & $2(1-6)$ \\
Digitation & $3,5 e v$ \\
Bristol stool scale (1-7) & \\
\hline
\end{tabular}

${ }^{a}$ Intensity of symptom: 0 , no; 1 , mild; 2 , moderate; 3 , severe; 4 , very severe.

HIVD, herniated intervertebral disc. 
with constipation with fecal incontinence had history of pelvic bone fracture and perineal injury $(n=1)$, jejunosigmoidostomy and hemorrhoidectomy $(\mathrm{n}=1)$, and operation for herniated intervertebral disc (HIVD) $(n=3)$. Three patients were myogenic (2 patients had internal sphincter injury and 1 patients had external sphincter injury) and 2 patients of neurogenic origin had spinal cord injury (one of them had cauda equine syndrome). One patient had fecal soiling with constipation. Combined disorders and constipation questionnaire results are shown in Table 1.

\section{Anal Sphincter Pressure}

The mean resting pressure was $51.4 \mathrm{mmHg}(16-131 \mathrm{mmHg})$ by water-perfused anorectal manometry and $51.9 \mathrm{mmHg}(22.5-$
94.6 $\mathrm{mmHg}$ ) by HRARM. The mean maximum squeezing pressure by water-perfused anorectal manometry $(146.3 \mathrm{mmHg}$ [46-325 $\mathrm{mmHg}]$ ) was not different from that of HRARM (137.7 $\mathrm{mmHg}$ [50.5-276.2 $\mathrm{mmHg}]$ ). The ratio of squeezing pressure to resting pressure by water-perfused anorectal manometry (2.6 [1.1-8.2]) was not different from that by HRARM (2.2 [1.4-5.9]) (Table 2). Both the resting and squeezing pressures by the 2 methods were strongly correlated (resting pressure: $r=0.746, P=0.002$; squeezing pressure: $r=0.921, P<$ 0.001) (Fig. 1).

\section{Attempted Defecation}

In attempted defecation, type I $(n=9)$, type II $(n=4)$, type

Table 2. Resting Pressure, Squeezing Pressure, S/R Ratio, Anal Canal Length, and Defecation Dynamic Parameters Determined by Conventional Water-perfused Anorectal Manometry and High-resolution Anorectal Manometry

\begin{tabular}{|c|c|c|c|}
\hline & Water-perfused anorectal manometry & HRARM & $P$-value \\
\hline Resting pressure $(\mathrm{mmHg})$ & & & 0.924 \\
\hline Median (range) & $48(16-131)$ & $49.8(22.5-94.6)$ & \\
\hline Mean $\pm \mathrm{SD}$ & $51.4 \pm 30.3$ & $51.9 \pm 25.2$ & \\
\hline Squeezing pressure $(\mathrm{mmHg})$ & & & 0.787 \\
\hline Median (range) & $105.5(46-325)$ & $121.4(50.5-276.2)$ & \\
\hline Mean $\pm \mathrm{SD}$ & $146.3 \pm 91.6$ & $137.7 \pm 81.7$ & \\
\hline $\mathrm{S} / \mathrm{R}$ ratio & & & 0.490 \\
\hline Median (range) & $2.6(1.1-8.2)$ & $2.2(1.4-5.9)$ & \\
\hline Mean $\pm \mathrm{SD}$ & $3.2 \pm 1.9$ & $2.9 \pm 1.9$ & \\
\hline Anal canal length $(\mathrm{cm})$ & $3.8(2.4-6.0)$ & $2.4(0.9-4.0)$ & 0.002 \\
\hline \multicolumn{4}{|l|}{ Defecation dynamic parameters } \\
\hline Rectoanal pressure gradient $(\mathrm{mmHg})$ & $-13(-40-98)$ & $-31.1(-69.3--6.6)$ & 0.054 \\
\hline Percentage of relaxation (\%) & $51.1(2.1-396)$ & $3.5(-78-41)$ & 0.009 \\
\hline
\end{tabular}

HRARM, high-resolution anorectal manometry; S/R ratio, squeezing pressure/resting pressure ratio.

A

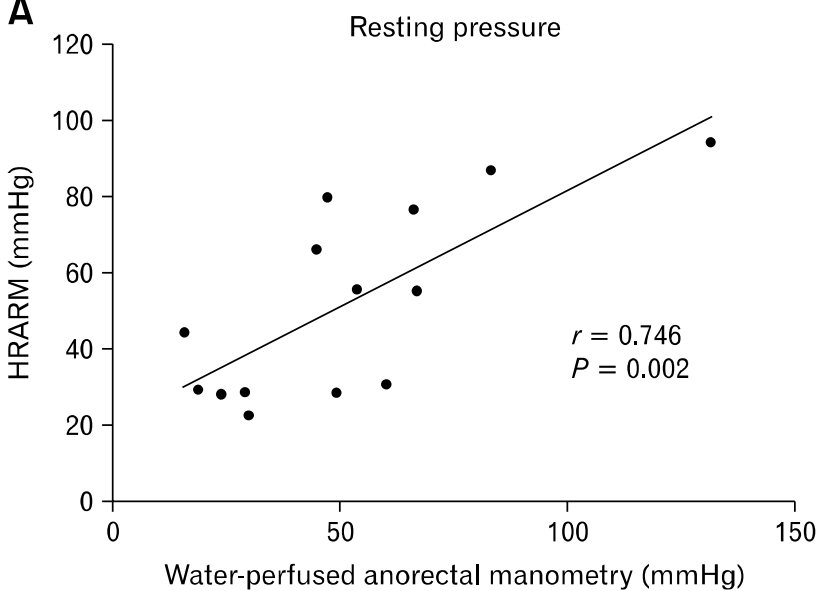

B

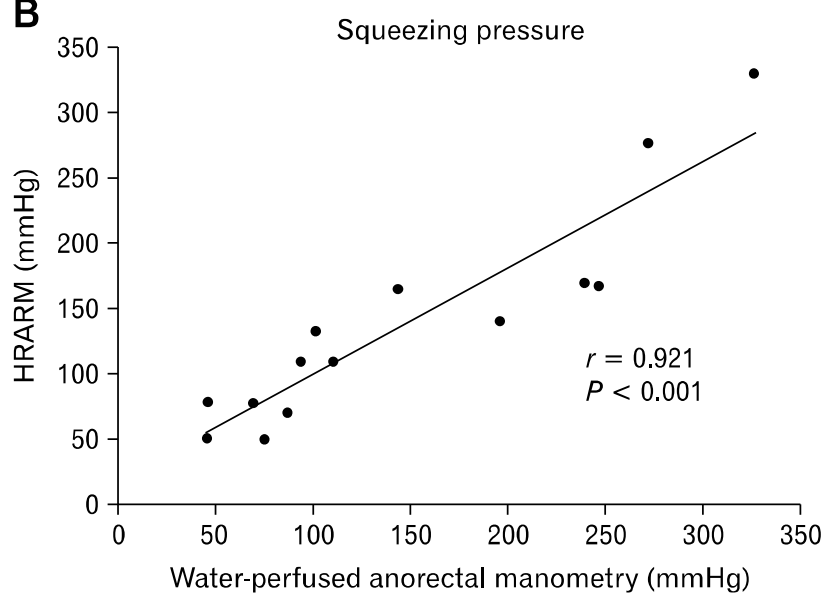

Figure 1. Correlations of resting (A) and squeezing (B) pressures between water-perfused anorectal manometry and high-resolution anorectal manometry (HRARM). 
III $(\mathrm{n}=0)$ and type IV $(\mathrm{n}=1)$ were present on water-perfused anorectal manometry according to Rao's classification; HRARM exhibited the same result. One equivocal case with water-perfused anorectal manometry was diagnosed as type I pelvic floor dyssynergia with HRARM. HRARM provides detailed pressure changes in external anal spincter or puborectalis muscle portion which improved assessment of anorectal disorders (Fig. 2).

\section{Rectoanal Inhibitory Reflex and Rectoanal Contractile Reflex}

Rectoanal inhibitory reflex is relaxation of the internal anal sphincter in response to increased pressure in the rectum tested by inflating a balloon in the lumen. Rectoanal inhibitory reflex by both methods was positive in all 14 patients. Amount of balloon
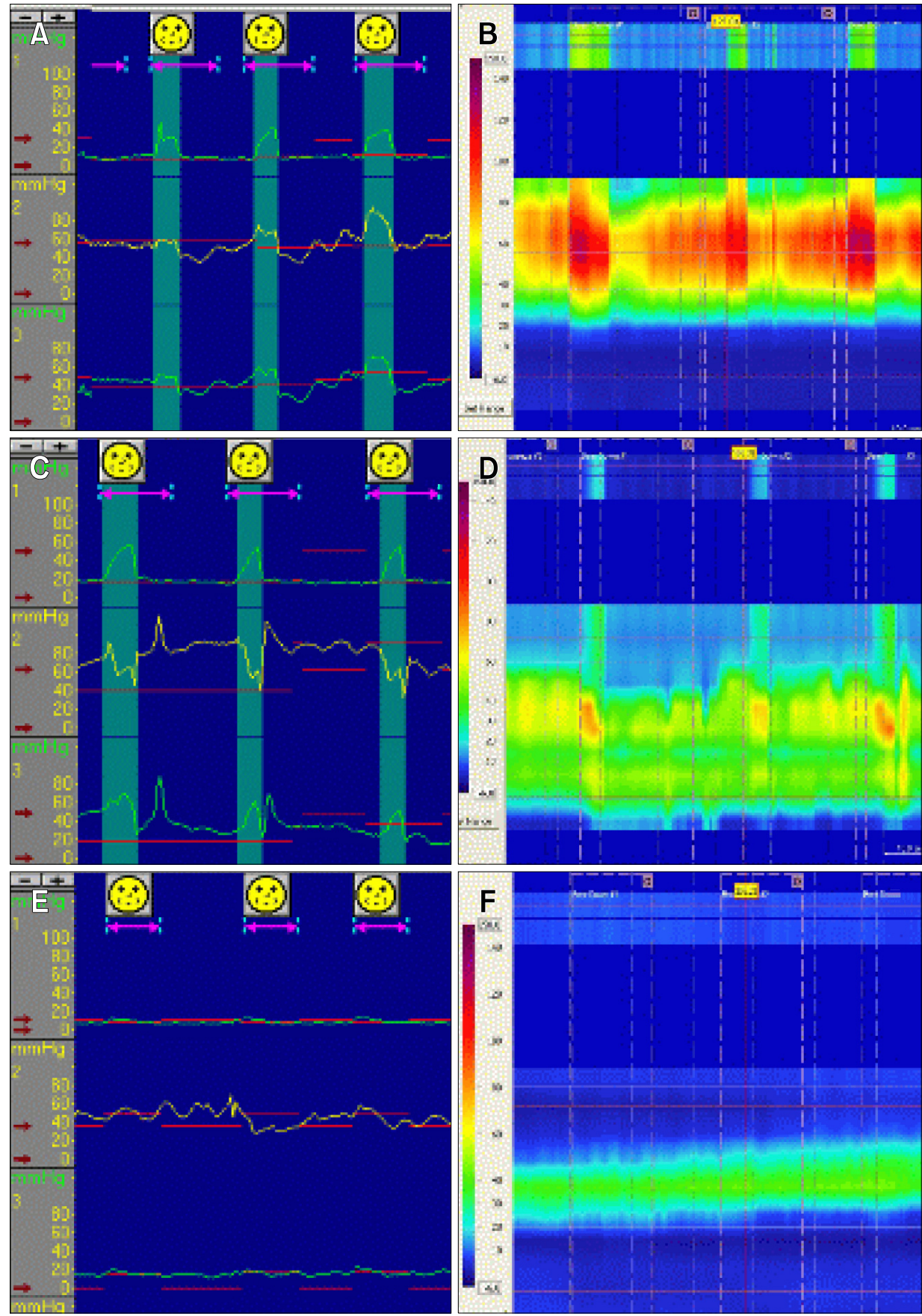

Figure 2. Cases of attempted defecation according to Rao's classification by water-perfused anorectal manometry and high-resolution anorectal manometry (HRARM). (A, B) Type I pelvic floor dyssynergia as determined by water-perfused anorectal manometry and HRARM. (C, D) This case shows equivocal result by water-perfused anorectal manometry. However, this case could be classified as type I pelvic floor dyssynergia by HRARM. HRARM revealed that puborectalis muscle portion was widely separated with anal sphincter portion. Equivocal relaxation of anal sphincter by water-perfused anorectal manometry might be due to the trapping of manometry sensor between two muscles. HRARM provides detailed pressure change in puborectalis muscle and anal spincter portion that may improves assessment of anorectal disorders. (E, F) Type IV pelvic floor dyssynergia as determined by water-perfused anorectal manometry and HRARM. 
inflation that was the volume threshold for first detected rectoanal inhibitory reflex was $25 \mathrm{~mL}(5-40 \mathrm{~mL})$ by water-perfused anorectal manometry and $30 \mathrm{~mL}(10-70 \mathrm{~mL})$ by HRARM with no statistical significance difference.

Rectoanal contractile reflex was also identical by both methods which was positive in 13 patients and negative in 1 patient with cuada equine syndrome. Pressure change during cough reflex was $54.8 \mathrm{mmHg}(0.0-169.6 \mathrm{mmHg})$ by water-perfused anorectal manometry and $63.7 \mathrm{mmHg}(0.0-98.5 \mathrm{mmHg})$ by HRARM. There were no statistically significant difference and correlation between 2 methods.

\section{Anal Canal Length and Defecation Dynamic Parameters}

Anal canal length was $3.8 \mathrm{~cm}(2.4-6.0 \mathrm{~cm})$ by water-perfused anorectal manometry and $2.4 \mathrm{~cm}(0.9-4.0 \mathrm{~cm})$ by HRARM and there was a statistically significant difference $(P=0.002)$. Rectoanal pressure gradient was $-13 \mathrm{mmHg}(-40-98 \mathrm{mmHg})$ by water-perfused anorectal manometry and $-31.1 \mathrm{mmHg}$ ( $-69.3--6.6 \mathrm{mmHg}$ ) by HRARM without significanct difference and correlation.

Percentage of relaxation was $51.1 \%(2.1-396.0 \%)$ by water-perfused anorectal manometry and $3.5 \%(-78-41 \%)$ by HRARM with statistical significant difference $(P=0.009)$. There was no correlation between 2 methods (Table 2$)$.

\section{Measurement Times}

The measurement time for HRARM was significantly shorter

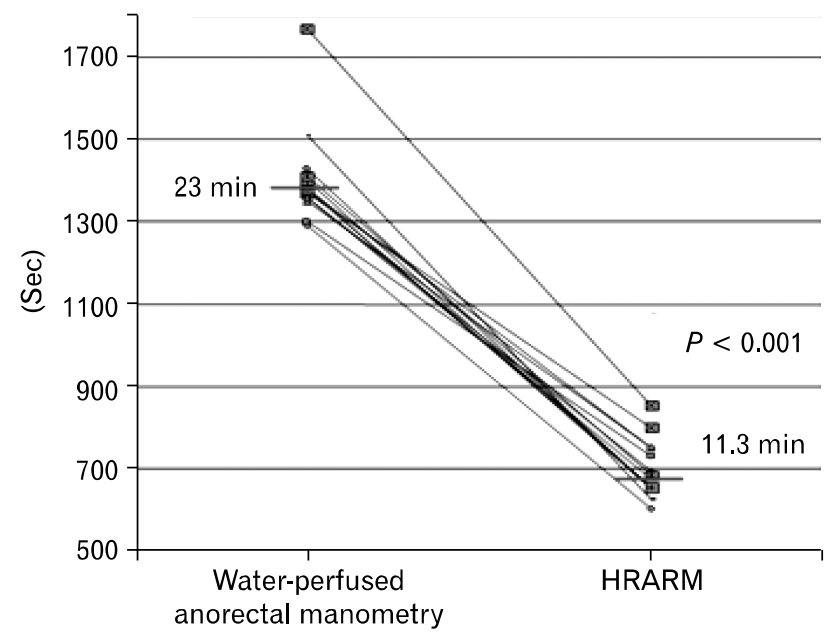

Figure 3. Comparison of measurement times for water-perfused anorectal manometry and high resolution anorectal manometry (HRARM) than that for water-perfused anorectal manometry (HRARM: median 11.3 minutes [range 10.0-14.2 minutes] vs water-perfused anorectal manometry: median 23 minutes [range 21.5-29.5 minutes], $P<0.001$ ) (Fig. 3).

\section{Discussion}

Recently HRM was introduced for measurement of gastrointestinal function. It is used usually to evaluate esophageal motility disorders, and has been reported to provide more physiological information with greater ease of interpretation. ${ }^{8-10}$ Conventional manometry typically utilizes pressure sensors spaced at 3-5 cm intervals, whereas high- resolution esophageal manometry makes use of more pressure sensors spaced at $1-\mathrm{cm}$ intervals, allowing collection of pressure data for the entire esophagus. Also, the direction, power and peristalsis of intra-esophageal pressure as presented in spatiotemporal plots allow clinicians to distinguish an abnormal from a normal esophageal motility pattern. ${ }^{11-13}$ Therefore, a high-resolution system is characterized by: (1) a simplified set up with improved sphincter localization, (2) elimination of movement artifacts, (3) simplified data interpretation, (4) the ability to perform a more sophisticated analysis $^{14}$, and (5) ease of reporting and storing the patient reports due to use of dedicated software.

The topic of this study was to evaluate the clinical usefulness of HRM for anorectal manometry as for esophageal manometry. Previous study comparing water-perfused anorectal manometry with $\mathrm{HRARM}^{6}$ was done simultaneously using water-perfused catheter and solid-state catheter for HRARM which lead to artifacts due to each catheter effect and not by physiologic condition. In this study, patients underwent both water-perfused anorectal manometry and HRARM on the same day in a random order.

The resting pressure $(r=0.746, P=0.002)$ and squeezing pressure $(r=0.921, P<0.001)$ were significantly correlated. Also, one equivocal case by water-perfused anorectal manometry according to Rao's classification of attempted defecation was diagnosed as type I pelvic floor dyssynergia with HRARM. HRARM provides precised and detailed pressure changes in internal and external anal spincters, and puborectalis muscle which improve assessment of anorectal disorders.

Anal canal length was longer by water-perfused anorectal manometry $(3.8 \mathrm{~cm}$ [2.4-6.0 cm] ) than by HRARM $(2.4 \mathrm{~cm}$ $[0.9-4.0 \mathrm{~cm}])$ and there was a statistically significant difference $(P=0.002)$. This could be from the artifacts produced by the movement from pulling the catheter in water-perfused anorectal 
manometry. During attempted defecation, rectoanal pressure gradient and percentage of relaxation were more variable by water-perfused anorectal manometry than by HRARM. These results might have been caused by movements of catheter in water-perfused anorectal manometry. In water-perfused anorectal manometry, the catheter is repositioned for measurements of each pressure that can lead to artifacts due to involuntary sphincter stimulation. By contrast, in HRARM, the catheter does not need to be changed so there is a less chance of artifacts from catheter movement with increased number of sensors within the catheter getting more rapid response upon pressure change, moreover, with shorter measurement time. Therefore, both the operator and patient are more comfortable during HRARM.

However, there is limitation of the small sample size. Although patients were more comfortable during HRARM, we did not assess this benefit objectively. Further studies are required to confirm HRARM superiority.

In conclusion, HRARM is likely to provide better physiological information and to require a shorter measurement time compared to water-perfused anorectal manometry.

\section{References}

1. Diamant NE, Kamm MA, Wald A, Whitehead WE. AGA technical review on anorectal testing techniques. Gastroenterology 1999;116: 735-760.

2. Jorge JM, Wexner SD. Anorectal manometry: techniques and clinical applications. South Med J 1993;86:924-931.

3. Fox M, Hebbard G, Janiak P, et al. High-resolution manometry predicts the success of oesophageal bolus transport and identifies clinically important abnormalities not detected by conventional manometry. Neurogastroenterol Motil 2004;16:533-542.

4. Bredenoord AJ, Weusten BL, Timmer R, Smout AJ. Sleeve sensor versus high-resolution manometry for the detection of transient lower esophageal sphincter relaxations. Am J Physiol Gastrointest Liver Physiol 2005;288:G1190-G1194.

5. Sadowski DC, Broenink L. High-resolution esophageal manometry: a time motion study. Can J Gastroenterol 2008;22:365-368.

6. Jones MP, Post J, Crowell MD. High-resolution manometry in the evaluation of anorectal disorders: a simultaneous comparison with water-perfused manometry. Am J Gastroenterol 2007;102:850-855.

7. Lee YY, Erdogan A, Rao SS. High resolution and high definition anorectal manometry and pressure topography: diagnostic advance or a new kid on the block? Curr Gastroenterol Rep 2013;15:360.

8. Clouse RE, Staiano A, Alrakawi A, Haroian L. Application of topographical methods to clinical esophageal manometry. Am J Gastroenterol 2000;95:2720-2730.

9. Pandolfino JE, Ghosh SK, Zhang Q, Jarosz A, Shah N, Kahrilas PJ. Quantifying EGJ morphology and relaxation with high-resolution manometry: a study of 75 asymptomatic volunteers. Am J Physiol Gastrointest Liver Physiol 2006;290:G1033-G1040.

10. Ghosh SK, Pandolfino JE, Zhang Q, Jarosz A, Shah N, Kahrilas PJ. Quantifying esophageal peristalsis with high-resolution manometry: a study of 75 asymptomatic volunteers. Am J Physiol Gastrointest Liver Physiol 2006;290:G988-G997.

11. Mellow MH. Esophageal motility during food ingestion: a physiologic test of esophageal motor function. Gastroenterology 1983;85: 570-577.

12. Fox MR, Bredenoord AJ. Oesophageal high-resolution manometry: moving from research into clinical practice. Gut 2008;57:405-423.

13. Conklin JL. Evaluation of esophageal motor function with high-resolution manometry. J Neurogastroenterol Motil 2013;19:281-294.

14. Pandolfino JE, Kahrilas PJ. New technologies in the gastrointestinal clinic and research: impedance and high-resolution manometry. World J Gastroenterol 2009;15:131-138. 